\title{
Israel flies high
}

\author{
Although often in the headlines for the wrong reasons, Israel is host to a strong economy. The fundamental drivers \\ of this economic success include a top-tier research system, which is worth examining more closely.
}

srael's success as a centre for innovation and entrepreneurship came to widespread attention in Dan Senor's and Saul Singer's 2009 book Start-up Nation. As late as the 1980 s, the country's economy was still essentially based on agriculture, mining and the secondary sectors. Given its limited resources, how did a young nation with a population of 8 million set the stage for what has come to be seen as an economic miracle?

A large part of the answer lies in a decades-long investment in education and research, technology, infrastructure and modern industry. Indeed, a deeper examination of Israel's strategy reveals that its economic success is no accident, and that it may serve as a prototype for others.

According to the Organisation for Economic Co-operation and Development (OECD), 46\% of 25-64-year-old Israelis are university-educated, ranked as second among OECD countries (tied with Japan and just after Canada). The country has maintained a large expenditure on education since the turn of the millennium. A well-educated population benefits the high-technology industry, which in turn pulls in cutting-edge research activities. Mandatory military service leads to a higher average age for Israelis obtaining their first university-level degree compared with many other countries, a greater exposure to life experience and the resulting maturity this provides gives students a better vision for their career. Those that do decide to pursue graduate studies and enter cutting-edge research therefore tend to have a clear motivation.

Israel's research universities are highly ranked in several scientific disciplines. Each year, around a third of all students in these universities are graduate students. Following their $\mathrm{PhD}$, a significant number of students choose to go abroad for further studies. But, unlike many European earlycareer researchers, who usually only find an academic position after several postdoctoral or research fellow contracts, most Israeli researchers return to their homeland after their first postdoctoral stint.

Israel has maintained a very high level of spending on research and development in the past 20 years. In 2017, it reached $4.54 \%$ of the growth domestic product, a figure topped only by South Korea's $4.55 \%$, and is almost twice that of the US, which is $2.79 \%$.

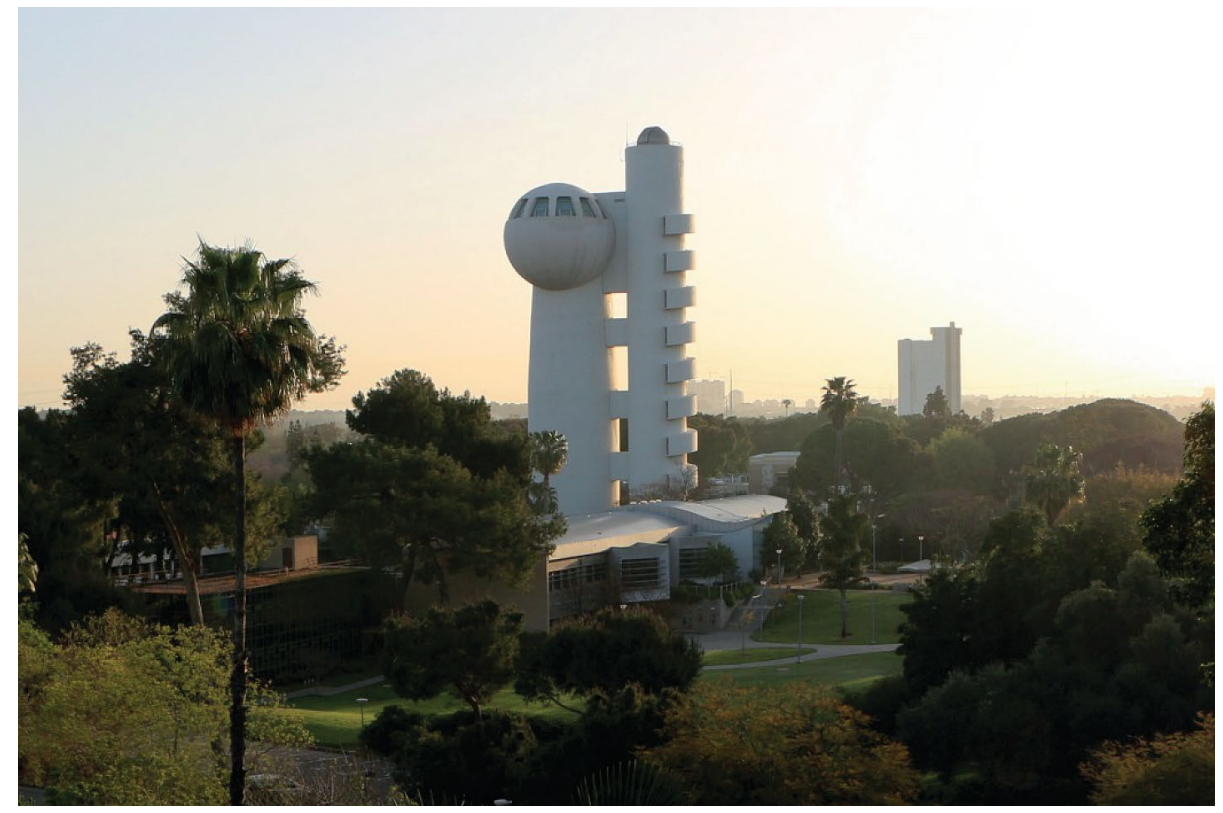

The Martin S. Kraar Observatory on the campus of the Weizmann Institute of Science, Israel.

Researchers at different stages of their career have various opportunities to get their research projects funded. The Israel Science Foundation (ISF), which is run by the Israel Academy of Sciences and Humanities, provides major support for basic scientific research in the country. In addition, Israeli researchers have received numerous prestigious grants from the European Research Council (ERC). In 2018, two Israeli organizations - the Weizmann Institute and the Hebrew University of Jerusalem - were listed in the top ten organizations hosting ERC principal investigators. Bilateral initiatives and joint research programmes, such as the USAIsrael Binational Science Foundation, the German-Israeli Foundation for Science Research and Development and the National Natural Science Foundation of China (NSFC)-ISF joint programme, also provide complementary funding, while strengthening collaboration between Israeli researchers and those from other countries.

In addition to fundamental research, universities are an essential point of contact between academia and industry. And here Israeli performance is exceptional. Each university in Israel has a technology transfer unit, supporting the commercialization of laboratory discoveries and promoting highpriority applications. Some of them, such as the YEDA Research and Development Company from the Weizmann Institute of Science, are among the most successful technology transfer companies in the world. Compared with their American counterparts, Israeli universities have been granted more patents relative to their expenditure on research and development. Government initiatives involving both universities and industry bring effective collaboration among disparate institutions. A good example is the Israel Nanotechnology Program launched in 2003: with a US\$300-million investment in its first 5 years, aimed at realizing a 10 -fold increase in the Israeli nanotechnology capability, it propelled Israel to the status of a heavyweight in the field.

Each country has its own strengths and unique circumstances. But the path picked by Israel in embedding its research infrastructure at the core of its strategy for ensuring the country's continued economic success is worth taking a closer look at.

Published online: 1 July 2019 https://doi.org/10.1038/s41567-019-0593-6 